\title{
Time trends of polycyclic aromatic hydrocarbon exposure in New York city from 2001 to 2012: Assessed by repeat air and urine samples
}

\author{
Kyung Hwa Jung a, Bian Liu ${ }^{\mathrm{a}}$, Stephanie Lovinsky-Desir ${ }^{\mathrm{b}}$, Beizhan Yan ${ }^{\mathrm{c}}$, David Camann ${ }^{\mathrm{d}}$, \\ Andreas Sjodin ${ }^{\mathrm{e}}$, ${\text { Zheng } \mathrm{Li}^{\mathrm{e}} \text {, } \text { Frederica Perera }}^{\mathrm{f}}$, Patrick Kinney ${ }^{\mathrm{f}}$, Steven Chillrud ${ }^{\mathrm{c}}$, \\ Rachel L. Miller ${ }^{\text {a,f,g,* }}$
}

\author{
a Division of Pulmonary, Allergy and Critical Care of Medicine, Department of Medicine, College of Physicians and Surgeons, Columbia University, PH8E-101, \\ 630W. 168 Street, New York, NY 10032, United States \\ ${ }^{\mathrm{b}}$ Division of Pediatric Pulmonary, Department of Pediatrics, College of Physicians and Surgeons, Columbia University, 3959 Broadway, CHC 7-745, New York, \\ NY 10032, United States \\ ${ }^{c}$ Lamont-Doherty Earth Observatory, Columbia University, 61 Rt, 9 W Palisades, NY 10964, United States \\ d Chemistry and Chemical Engineering Division, Southwest Research Institute, 6220 Culebra Road, San Antonio, TX 78228, United States \\ e Centers for Disease Control and Prevention, National Center for Environmental Health, Division of Laboratory Sciences, Organic Analytical Toxicology \\ Branch, Atlanta, GA, United States \\ f Columbia Center for Children's Environmental Health, Mailman School of Public Health, Department of Environmental Health Sciences, Columbia University, \\ 722W. 168 Street, New York, NY 10032, United States \\ g Division of Pediatric Allergy and Immunology, Department of Pediatrics, College of Physicians and Surgeons, Columbia University, PH8E-101, 630W. 168 \\ Street, New York, NY 10032, United States
}

\section{A R T I C L E I N F O}

\section{Article history:}

Received 26 September 2013

Received in revised form

19 February 2014

Accepted 21 February 2014

Available online 5 April 2014

Keywords:

Temporal variations

Polycyclic aromatic hydrocarbons

Urinary metabolites

Repeat exposure

Trafficemission

Heating oil combustion

\begin{abstract}
A B S T R A C T
Background: Exposure to air pollutants including polycyclic aromatic hydrocarbons (PAH), and specifically pyrene from combustion of fuel oil, coal, traffic and indoor sources, has been associated with adverse respiratory health outcomes. However, time trends of airborne PAH and metabolite levels detected via repeat measures over time have not yet been characterized. We hypothesized that PAH levels, measured repeatedly from residential indoor and outdoor monitors, and children's urinary concentrations of PAH metabolites, would decrease following policy interventions to reduce traffic-related air pollution.

Methods: Indoor PAH (particle- and gas-phase) were collected for two weeks prenatally ( $n=98$ ), at age 5/6 years $(n=397)$ and age $9 / 10$ years $(n=198)$ since 2001 and at all three age-points $(n=27)$. Other trafficrelated air pollutants (black carbon and $\mathrm{PM}_{2.5}$ ) were monitored indoors simultaneous with PAH monitoring at ages 5/6 $(n=403)$ and 9/10 $(n=257)$ between 2005 and 2012. One third of the homes were selected across seasons for outdoor $\mathrm{PAH}, \mathrm{BC}$ and $\mathrm{PM}_{2.5}$ sampling. Using the same sampling method, ambient $\mathrm{PAH}, \mathrm{BC}$ and $\mathrm{PM}_{2.5}$ also were monitored every two weeks at a central site between 2007 and 2012. PAH were analyzed as

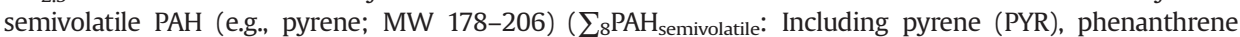
(PHEN), 1-methylphenanthrene (1-MEPH), 2-methylphenanthrene (2-MEPH), 3-methylphenanthrene (3-MEPH), 9-methylphenanthrene (9-MEPH), 1,7-dimethylphenanthrene (1,7-DMEPH), and 3,6-dimethyl-

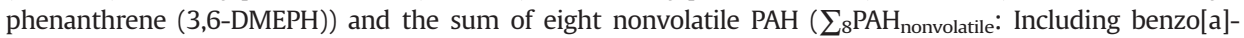
anthracene (BaA), chrysene/iso-chrysene (Chry), benzo[b]fluoranthene (BbFA), benzo[k]fluoranthene (BkFA), benzo[a]pyrene (BaP), indeno[1,2,3-c,d]pyrene (IP), dibenzo[a,h]anthracene (DahA), and benzo[g,h,i]perylene (BghiP); MW 228-278). A spot urine sample was collected from children at child ages 3, 5, 7 and 9 between 2001 and 2012 and analyzed for 10 PAH metabolites.

Results: Modest declines were detected in indoor BC and $\mathrm{PM}_{2.5}$ levels between 2005 and 2012 (Annual percent change $[\mathrm{APC}]=-2.08 \%[p=0.010]$ and $-2.18 \%[p=0.059]$ for $\mathrm{BC}$ and $\mathrm{PM}_{2.5}$, respectively), while a trend of increasing pyrene levels was observed in indoor and outdoor samples, and at the central site during the comparable time periods $(\mathrm{APC}=4.81 \%, 3.77 \%$ and $7.90 \%$, respectively; $p<0.05$ for all). No significant time
\end{abstract}

\footnotetext{
Abbreviations: APC, annual percent change; BC, black carbon; CCCEH, Columbia Center for Children's Environmental Health; DEP, diesel exhaust particle; EC, elemental

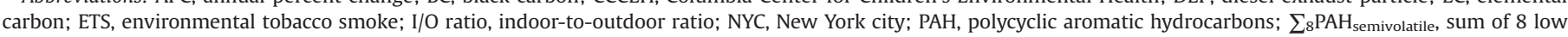

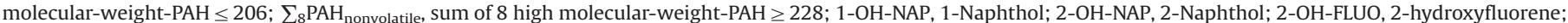
3-OH-FLUO, 3-hydroxyfluorene; 9-OH-FLUO, 9-hydroxyfluorene; 1-OH-PHEN, 1-hydroxyphenanthrene; 2-OH-PHEN, 2-hydroxyphenanthrene; 3-OH-PHEN, 3hydroxyphenanthrene; 4-OH-PHEN, 4-hydroxyphenanthrene; 1-OH-PYR, 1-hydroxypyrene; PM, particulate matter; PUF, polyurethane foam

* Corresponding author at: Division of Pulmonary, Allergy and Critical Care of Medicine, Department of Medicine, College of Physicians and Surgeons, Columbia University, PH8E-101, 630W. 168 Street, New York, NY 10032, United States. Fax: +1212 3052277.

E-mail address: rlm14@cumc.columbia.edu (R.L. Miller).
} 


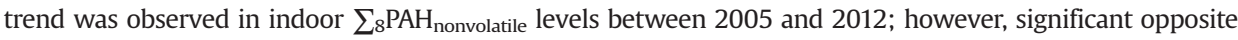
trends were detected when analyzed seasonally (APC $=-8.06 \%[p<0.01], 3.87 \%[p<0.05]$ for nonheating and heating season, respectively). Similarly, heating season also affected the annual trends (2005-2012) of other air pollutants: the decreasing BC trend (in indoor/outdoor air) was observed only in the nonheating season, consistent with dominating traffic sources that decreased with time; the increasing pyrene trend was more apparent in the heating season. Outdoor $\mathrm{PM}_{2.5}$ levels persistently decreased over time across the seasons. With the analyses of data collected over a longer period of time (2001-2012), a decreasing trend was observed in pyrene $(\mathrm{APC}=-2.76 \% ; p<0.01)$, mostly driven by measures from the nonheating season $(\mathrm{APC}=-3.54 \% ; p<0.01)$. In contrast, levels of pyrene and naphthalene metabolites, 1-hydroxypyrene and 2-naphthol, increased from 2001 to 2012 (APC $=6.29 \%$ and 7.90\% for 1-hydroxypyrene and 2-naphthol, respectively; $p<0.01$ for both).

Conclusions: Multiple NYC legislative regulations targeting traffic-related air pollution may have led to decreases in $\sum_{8} \mathrm{PAH}_{\text {nonvolatile }}$ and $\mathrm{BC}$, especially in the nonheating season. Despite the overall decrease in pyrene over the 2001-2012 periods, a rise in pyrene levels in recent years (2005-2012), that was particularly evident for measures collected during the heating season, and 2-naphthol, indicates the contribution of heating oil combustion and other indoor sources to airborne pyrene and urinary 2-naphthol.

(c) 2014 Elsevier Inc. All rights reserved.

\section{Introduction}

Exposure to traffic-related air pollutants such as polycyclic aromatic hydrocarbons (PAH), black carbon (BC), and particulate matter less than $2.5 \mu \mathrm{m}$ in diameter $\left(\mathrm{PM}_{2.5}\right)$ may induce the development of asthma or trigger asthma symptoms (Jung et al., 2012a, 2012b; Miller et al., 2004; Perzanowski et al., 2013; Rosa et al., 2011; Spira-Cohen et al., 2011). For example, our group at the Columbia Center for Children's Environmental Health (CCCEH) reported that young children from Northern Manhattan who are exposed repeatedly to high PAH (i.e., semivolatile pyrene) during prenatal and early childhood periods may be at greater risk of having asthma (Jung et al., 2012b). Several of the PAH also have been associated with the development of indoor allergen sensitization in early childhood (Miller et al., 2010; Perzanowski et al., 2013).

Major outdoor sources of $\mathrm{PAH}, \mathrm{BC}$ and $\mathrm{PM}_{2.5}$ include traffic emissions derived from diesel/gasoline vehicles and heating and power sources such as oil, coal, and biomass, and indoor sources include cooking, residential heating, environmental tobacco smoke (ETS), and candles/incense (Lewtas, 2007). While nonvolatile PAH (i.e., high-molecular weight $\mathrm{PAH} \geq 228$; e.g., benzo(a)pyrene) are generated predominantly by incomplete combustion, semivolatile $\mathrm{PAH}$ (i.e., low-molecular weight $\mathrm{PAH} \leq 206$; e.g. pyrene) are emitted from both incomplete combustion and petrogenic (i.e., produced by petroleum) sources such as direct evaporation from petroleum products, oil leaks, and the ground (Ma et al., 2010; Zhang and Tao, 2009). Major sources of New York City (NYC) ambient $\mathrm{PM}_{2.5}$ concentrations include long-range transported sulfate, upwind photochemical production of sulfate and other secondary organic carbon, traffic emissions, and steel dust (Cyrys et al., 2003; Lall et al., 2011). Residential and commercial heating oil (residual oil; types \#4 and \#6) combustion also is considered a major source of NYC BC and $\mathrm{PM}_{2.5}$ (Cornell et al., 2012). The observation that indoor/outdoor (I/O) concentration ratios of semivolatile PAH are greater than 1 in NYC homes indicates that indoor sources of semivolatile PAH can be important. The $\mathrm{I} / \mathrm{O}$ ratios of nonvolatile $\mathrm{PAH}$ and $\mathrm{BC}$ less than 1 or close to 1 suggest that the indoor concentrations of nonvolatile $\mathrm{PAH}$ and $\mathrm{BC}$ arise predominantly from the transport of outdoor air into the indoor environment (Jung et al., 2010a; Kinney et al., 2002).

In an effort to diminish levels of air pollutants, NYC implemented multiple legislative regulations since 2000 . These included the conversion to ultra-low sulfur diesel fuel (ULSD) ${ }^{1}$ and use of the best available retrofit technology (BART) ${ }^{1}$ on city-owned or operated diesel fuel-powered vehicles such as garbage trucks, school buses and fleet trucks, and non-road vehicles (e.g., construction vehicles, generators) in 2007 as well as the conversion and replacement of Metropolitan Transportation Authority diesel vehicles to low emission diesel and alternative fuel vehicles in 2000 (MTA, 2013). In 2009, the existing idling law was strengthened further near school districts; idling in excess of $1 \mathrm{~min}$ was prohibited near any public or non-public school. ${ }^{2}$ More recently, in 2011, the Clean Heat Rule was initiated to phase out the use of dirty fuel oils (low grade, types \#4 and \#6) for heating by 2012 with a conversion to a ultra-low sulfur version of \#2 oil, or natural gas, as well as prohibiting any new boilers issued for \#4 or \#6 fuel oil and eliminating renewals issued for \#6 fuel oil.

Coincident with Clean Air Act provisions since 1970s and the earlier NYC bus fleet-wide plan to reduce diesel emissions, and increase the use of cleaner fuels since 2000, our previous study found that the average levels of nonvolatile PAH in NYC, measured using 48-h personal air monitoring in our cohort, have declined between 1998 and 2006 (Narvaez et al., 2008). However, time trends of airborne PAH and PAH metabolite levels via repeat measures in the same homes and individuals over time have not been previously characterized. The objectives of this study were to (1) determine annual trends in PAH and other traffic-related pollutants (i.e., BC and $\mathrm{PM}_{2.5}$ ) using a more comprehensive and longer monitoring data set that included repeated measures from children's indoor and outdoor environments prenatally through age $9 / 10$ as well as from the central monitoring site; and (2) examine annual trends of PAH metabolites in urine after adjusting for potential covariates such as age, race/ ethnicity and indoor sources. Our approach was to utilize data on airborne traffic-related air pollutants from children's residences and PAH urinary metabolites collected as part of the CCCEH longitudinal birth cohort study in Northern Manhattan and the South Bronx, New York. We hypothesized that (1) airborne $\mathrm{PAH}, \mathrm{BC}$ and $\mathrm{PM}_{2.5}$ levels, measured repeatedly from indoor and outdoor residential monitors and at the central site, and PAH metabolite levels would decrease from 2001 to 2012, in parallel with policy interventions to reduce traffic-related air pollution and (2) decreasing trends of traffic-related air pollutants would be more apparent during the nonheating season when residential heating oil is not used.

\section{Materials and methods}

\subsection{Study design and population}

Nonsmoking African American or Dominican women ages 18-35 living in Northern Manhattan and the South Bronx were enrolled during pregnancy 
( $n=727$ ) between March 1998 and August 2006 with an average of 81 births $( \pm 37, S D)$ per year, and their children were followed prospectively. Each age point encompassed 4-9 years. Questionnaires were administered to the participants prenatally, every 3 months through age 2 years, and every 6 months through age 5 years, and annually thereafter. Participants selected for the present analysis had at least one residential air monitoring sample collected prenatally, at age 5/6 or 9/10 years or a urine sample analyzed at age $3,5,7$ or 9 years (Fig. 1). Levels of air pollutants were measured from residential indoor monitors for a subset of participants during pregnancy $(n=98), 397$ of their children at age 5-6 years, and 143 at age 9-10 years. Among children with measures prenatally and age 5-6 $(n=62), 27$ children were followed further through age 9-10 (Fig. 2). A total of $n=179$ children had urine samples collected at all four age-points. Among those with urinary PAH metabolites, 69\% (297/431 at age 5) and 57\% (143/253 at age 9) of children had concurrent measures of airborne indoor $\mathrm{PAH}$.

The study was approved by the Columbia University Institutional Review Board and the Centers for Disease Control and Prevention (CDC) and written informed consent was obtained from all study participants.

\subsection{Air monitoring}

Prenatal two-week integrated indoor monitoring was conducted continuously beginning during the 32nd week of pregnancy until delivery between 2001 and 2004 (Whyatt et al., 2007). Those consecutive indoor PAH levels were fairly stable, with an intra-class correlation coefficient of 0.65 for samples collected during the last 6-8 weeks of pregnancy (Rundle et al., 2012). Because of the high correlations among sequential indoor samples $\left(r=0.65\right.$ and 0.81 for $\sum_{8} \mathrm{PAH}_{\text {nonvolatile }}$ and pyrene, respectively, $p<0.01$ ), only the first valid indoor measure was included for data analysis to represent indoor PAH exposure in that specific year of pregnancy.

Similarly, air monitors were placed in a room where the child spent most of his or her time for two weeks between 2005 and 2011 at age 5 through 6 and between

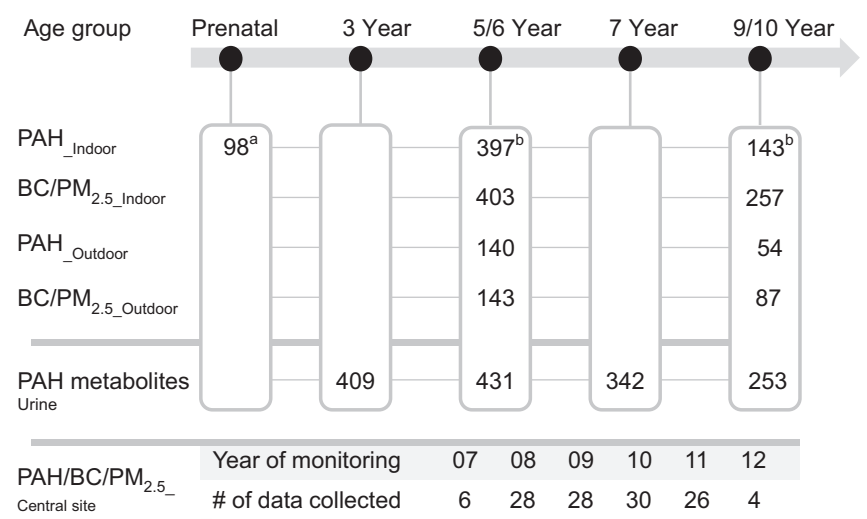

Fig. 1. Pollutant data available in various ages of subjects (prenatal through age 9/10) and various sampling matrices. At each age including prenatally, subjects were enrolled over 4-7 years for air pollution and 5-9 years for urinary PAH metabolites. ${ }^{\mathrm{a}} 9 \mathrm{PAH}$ ( 8 nonvolatile $\mathrm{PAH}$ and one semivolatile pyrene) were measured. ${ }^{\mathrm{b}} 16 \mathrm{PAH}$ ( 8 nonvolatile and 8 semivolatile) were measured.

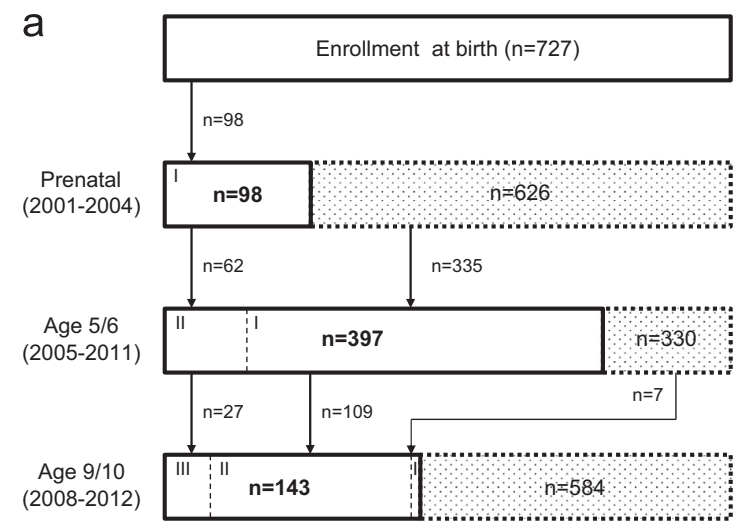

$=$ Children with residential indoor PAH data

$=$ Children without residential indoor $\mathrm{PAH}$ data
2008 and 2012 at age 9 through 10 years (Jung et al., 2010a). Nine PAH (eight nonvolatile $M W \geq 228$ plus one semivolatile pyrene; analyzed separately due to their minimal correlation with each other) were monitored prenatally. An additional 7 semivolatile PAH ( $178 \leq \mathrm{MW} \leq 206$; phenanthrene and methylphenanthrenes), $\mathrm{PM}_{2.5}$ and $\mathrm{BC}$ were added as target compounds in later ages (Jung et al., $2010 \mathrm{~b})$. One third of the homes were selected across all 4 seasons for simultaneous outdoor samplings of $\mathrm{PAH}, \mathrm{BC}$ and $\mathrm{PM}_{2.5}$ at both ages 5/6 (2006-2011) and 9/10 (2008-2012) (Fig. 1). All airborne PAH samples were collected and extracted following the same method at Southwest Research Institute, i.e., a single soxhlet extraction of both the filter and PUF together as described previously (Jung et al., 2010a; Whyatt et al., 2007).

Ambient levels of $\mathrm{PAH}, \mathrm{BC}$, and $\mathrm{PM}_{2.5}$ were measured at the CCCEH monitoring station (central site) every two weeks starting from October 2007 to July 2012 (Fig. 1). BC and $\mathrm{PM}_{2.5}$ were collected on Teflon filter samples with a flow rate of $1.5 \mathrm{~L} / \mathrm{min}$ for two weeks, leading to an average sampling volume of $30.1 \mathrm{~m}^{3}$. BC was estimated by multi-wavelength integrating sphere method (Yan et al., 2011) and filters were pre- and post-weighted on a microbalance after being equilibrated under a temperature and humidity controlled environment for at least $24 \mathrm{~h}$ for measurement of $\mathrm{PM}_{2.5}$ (Jung et al., 2010a).

Daily maximum eight-hour average ambient ozone concentrations for NYC were measured by the New York State Department of Environmental Conservation between 2001 and 2012 (http://www.epa.gov/airdata/). Data for two monitoring sites in the Bronx located within the study area (Intermediate School 52 and Botanical Gardens) were used. Ozone concentrations were averaged over the corresponding two-week sampling period for each subject and the central site for the analysis.

\subsection{PAH biomarker collection and analysis}

A spot urine sample was collected from children at ages 3, 5, and 7 years concurrent with the administration of the questionnaire. At age 9, a urine sample was collected at the start or the end of the two-week integrated indoor air monitoring. The urinary concentrations of $10 \mathrm{PAH}$ metabolites, including 1-hydroxy pyrene (1-OH-PYR), were measured at the Centers for Disease Control and Prevention (CDC) (Li et al., 2006; Miller et al., 2010). The limit of detection (LOD) ranged from 10 to $40 \mathrm{ng} / \mathrm{l}$, depending on the analytes; values below LOD were recoded as half of LOD. Specific gravity levels were measured using a handheld refractometer to permit adjustment for dilution of the urine. Urinary PAH metabolite concentrations were adjusted by specific gravity using a formula developed by Hauser et al. (2004) and adapted to a pediatric population, consistent with prior analyses (Hauser et al., 2004; Miller et al., 2010). The ten urinary metabolites of PAH monitored were: 1-naphthol (1-OH-NAP), 2-naphthol (2-OH-NAP), 2-hydroxyfluorene (2-OH-FLUO), 3-hydroxyfluorene (3-OH-FLUO), 9-hydroxyfluorene (9-OH-FLUO), 1-hydroxyphenanthrene (1-OH-PHEN), 2hydroxyphenanthrene (2-OH-PHEN), 3-hydroxyphenanthrene (3-OH-PHEN), 4hydroxyphenanthrene (4-OH-PHEN), and 1-hydroxypyrene (1-OH-PYR).

\subsection{Questionnaires}

Questionnaires were administered to the participant to collect information on the subject characteristics (e.g., race/ethnicity, sex, and maternal education) and home environmental characteristics (e.g., exposure to ETS, changes in address

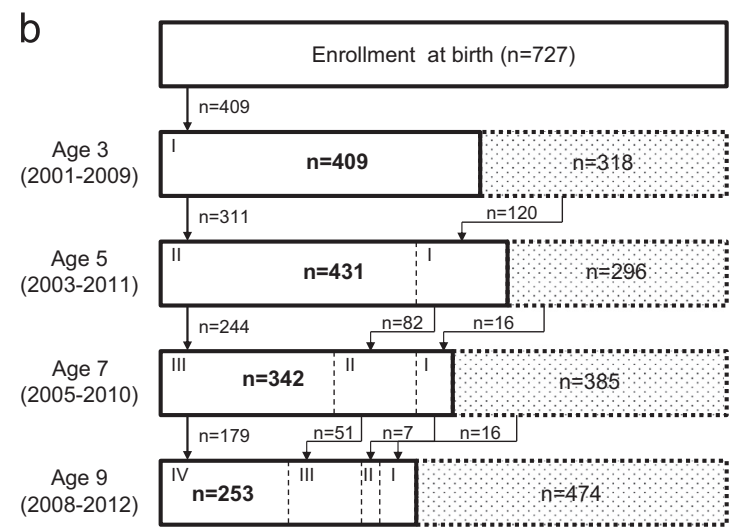

Children with urinary PAH metabolite data

= Children without urinary PAH metabolite data

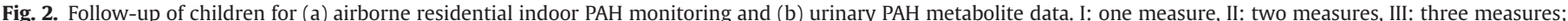
IV: four measures; only 27 children had indoor monitoring data at all three age-points and 179 children had urinary PAH metabolite data at all four time-points. 
between exposure measurements, housing crowding, type of cooking appliance and use of candles or incense).

\subsection{Statistical analysis}

Unless specified, the levels of air pollutants ( $\mathrm{PAH}, \mathrm{BC}$, and $\mathrm{PM}_{2.5}$ ) and urinary PAH metabolites were natural log-transformed. Data from the central monitoring site were analyzed using linear regression modeling controlling for heating season (defined as any sampling that was initiated October 1-April 30) and ambient ozone concentrations, that induced substantial chemical degradation of PAH in the air or on the air sampler filter (Jung et al., 2010a). Year of monitoring, as an interval variable, was analyzed as the independent predictor in the central site linear regression models and the regression models were further run following stratification by heating season.

The effect of year of monitoring on repeated measures of indoor and outdoor air pollutants and urinary PAH metabolites was analyzed further in a model using generalized estimating equations (GEE) with robust standard errors, after controlling for common potential covariates that may affect the levels of indoor air pollutants. They include race/ethnicity (African American versus Hispanic), maternal education (high school degree and above), current ETS exposure (smokers in the house), gas stove cooking, housing crowding (the number of people living in the house), moved (changes in address between exposure measurements) and heating season. Further, ambient ozone concentrations were added to the outdoor $\mathrm{PAH}$ model after natural-log transformation. Urinary specific gravity was included as the correction covariate in models involving PAH metabolites. Age of child at the urine sample collections, as an ordinal variable, also was added to the models because basal metabolic rate is known to increase with age among children 2-16 years of age (Spurr et al., 1992). Annual percent change (APC) in air pollutant was calculated by $100\left[\exp \left(\log \_\beta_{\text {adj }}\right)-1\right]$ where $\log \_\beta_{\text {adj }}$ is a coefficient of air pollutant in an adjusted model. Correlation coefficients between indoor airborne PAH and specific gravity-adjusted PAH metabolites were calculated using Pearson's correlation. All analyses were performed using PASW Statistic version 18.0 (SPSS Inc., Chicago, IL, USA) where $p<0.05$ was considered statistically significant.

\section{Results}

\subsection{Study cohort and home characteristics}

Children who underwent residential monitoring did not differ demographically from the CCCEH children who were excluded from the analysis, with the exception of lower maternal education level during the prenatal period among those included (Table 1). The group of children who had urinary metabolite data and were included in the analysis included more African Americans across all ages, as compared to those not included. Among those children analyzed with residential monitoring data, 36.1\% reported ETS exposure during the prenatal period with significantly lower rates at age $5(16.7 \%)$ and age $9(12.1 \%)$ (Table $1, \chi^{2}$ test; $p<0.001$ ).

\subsection{Year of monitoring as a predictor of airborne $P A H$ and $P A H$ metabolites}

The annual geometric mean concentrations of air pollutants and PAH metabolites are presented by different sampling matrices and age group in Supplemental Table 1. Annual trends of air pollution were examined first with the data collected from the central site. Pyrene, but not $\sum_{8} \mathrm{PAH}_{\text {nonvolatile }}$ nor $\sum_{8} \mathrm{PAH}_{\text {semivolatile, increased }}$ between 2007 and 2012 (Fig. 3, linear regression, $A P C=7.90 \%$, $p<0.001$ ); this increasing trend was driven mostly by observations from the heating season $(A P C=11.0 \%$ during heating season, $p<0.001$ ). Levels of $\mathrm{BC}$ and $\mathrm{PM}_{2.5}$ at the central site showed a decreasing trend (linear regression, APC [ $p$-value $]=-3.10 \%$ $[p=0.138]$ for $\mathrm{BC}$ and $-5.35 \%[p=0.042]$ for $\left.\mathrm{PM}_{2.5}\right)$.

Examination of annual trends of residential outdoor data collected between 2006 and 2012 (total $n=194 ; n=140$ at age 5/ 6 and $n=54$ at age 9/10) corroborated the increasing trends of ambient pyrene concentrations in the central site (Table 2, GEE $\mathrm{APC}=3.77 \% ; p<0.05)$. In contrast, a statistically significant decreasing $\mathrm{PM}_{2.5}$ and borderline significant decreasing $\mathrm{BC}$ trends were detected in residential outdoors (Table 2. APC $=-5.35 \%$ $[p<0.01]$ and $\mathrm{APC}=-2.08 \%[p=0.057]$ for $\mathrm{PM}_{2.5}$ and $\mathrm{BC}$, respectively). Similar to those observed in residential outdoor measures, consistent and more robust patterns of pyrene and $\mathrm{BC}$ in annual trends were observed when the indoor measures at age 5/6 and age $9 / 10$ were merged and assessed $(n=527)$. For example, indoor pyrene as well as other individual semivolatile PAH significantly increased between 2005 and 2012 (Table 2; see Supplementary Table 2 for individual $\mathrm{PAH})$, while significant declines were detected in indoor $\mathrm{BC}(\mathrm{APC}=-2.08 \%, p=0.010)$. No significant time trend was observed in indoor $\sum_{8} \mathrm{PAH}_{\text {nonvolatile levels between }}$ 2005 and 2012; however, significant opposite trends were detected when analyzed seasonally (Table 3. APC $=-8.06 \%$ [ $p<0.01]$ for nonheating, 3.87\% $[p<0.05]$ for heating season). Indeed, heating season affected annual trends (2005-2012) of other air pollutants as well: the decreasing BC trends (both in indoor and outdoor air) were observed only in the nonheating

Table 1

Study cohort characteristics by child's age group. ${ }^{\text {a }}$

\begin{tabular}{|c|c|c|c|c|c|c|c|c|}
\hline \multirow[b]{2}{*}{$\mathrm{N}$} & \multirow{2}{*}{$\begin{array}{l}\text { CCCEH } \\
\text { Cohort } \\
727\end{array}$} & \multicolumn{3}{|c|}{ Children with residential monitoring } & \multicolumn{4}{|c|}{ Children with urine collection } \\
\hline & & $\begin{array}{l}\text { Prenatal } \\
\quad 98\end{array}$ & $\begin{array}{c}5 \text { Year } \\
397\end{array}$ & $\begin{array}{c}9 \text { Year } \\
143\end{array}$ & $\begin{array}{c}3 \text { Year } \\
409\end{array}$ & $\begin{array}{c}5 \text { Year } \\
431\end{array}$ & $\begin{array}{c}7 \text { Year } \\
342\end{array}$ & $\begin{array}{l}9 \text { Year } \\
253\end{array}$ \\
\hline \multicolumn{9}{|c|}{ Subject characteristics } \\
\hline $\begin{array}{l}\text { Dominican } \\
\text { African American }\end{array}$ & $\begin{array}{l}473(65.1) \\
254(34.9)\end{array}$ & $\begin{array}{l}67(68.4) \\
31(31.6)\end{array}$ & $\begin{array}{l}256(64.5) \\
141(35.5)\end{array}$ & $\begin{array}{l}85(59.4) \\
58(40.6)\end{array}$ & $\begin{array}{l}244(59.7)^{*} \\
165(40.3)\end{array}$ & $\begin{array}{l}264(61.3)^{*} \\
167(38.7)\end{array}$ & $\begin{array}{l}189(\mathbf{5 5 . 3})^{*} \\
153(44.7)\end{array}$ & $\begin{array}{l}143(56.5)^{*} \\
110(43.5)\end{array}$ \\
\hline $\begin{array}{l}\text { Sex of child } \\
\text { Girls } \\
\text { Boys }\end{array}$ & $\begin{array}{l}376(51.7) \\
351(48.3)\end{array}$ & $\begin{array}{l}52(53.1) \\
46(46.9)\end{array}$ & $\begin{array}{l}213(53.7) \\
184(46.3)\end{array}$ & $\begin{array}{l}77(53.8) \\
66(46.2)\end{array}$ & $\begin{array}{l}218(53.3) \\
191(46.7)\end{array}$ & $\begin{array}{l}233(54.1) \\
198(45.9)\end{array}$ & $\begin{array}{l}184(53.8) \\
158(46.2)\end{array}$ & $\begin{array}{l}135(53.4) \\
118(46.6)\end{array}$ \\
\hline $\begin{array}{l}\text { Maternal education } \\
\geq \text { High school }\end{array}$ & $456(64.0)$ & $52(53.1)^{*}$ & $246(62.1)$ & 85 (59.9) & $255(63.3)$ & $272(64.6)$ & $217(65.4)$ & $157(63.3)$ \\
\hline $\begin{array}{l}\text { Home characteristic } \\
\text { Smoker in home }{ }^{\mathrm{b}} \\
\text { Gas stove cooking } \\
\text { Burning candles } \\
\text { Burning incense }\end{array}$ & $\begin{array}{l}246(34.3) \\
686(95.5) \\
357(49.4) \\
165(23.1)\end{array}$ & $\begin{array}{l}35(36.1) \\
92(97.9) \\
51(52.6) \\
20(20.6)\end{array}$ & $\begin{array}{c}66(16.9) \\
370(\mathbf{9 4 . 4})^{*} \\
187(47.5) \\
79(20.1)\end{array}$ & $\begin{array}{r}17(12.1) \\
128(91.4) \\
66(47.1) \\
29(20.7)\end{array}$ & $\begin{array}{r}87(21.3) \\
379(93.1) \\
196(48.3) \\
90(22.2)\end{array}$ & $\begin{array}{c}79(18.6) \\
399(93.9)^{*} \\
201(47.0) \\
102(23.9)\end{array}$ & $\begin{array}{c}61(18.1) \\
315(\mathbf{9 2 . 9})^{*} \\
154(45.2) \\
77(22.6)\end{array}$ & $\begin{array}{r}32(13.0) \\
229(92.7) \\
110(44.5) \\
55(22.4)\end{array}$ \\
\hline
\end{tabular}

* Boldface type indicates statistical significance with $p$-value $<0.05$.

${ }^{a}$ Includes participants with at least one residential air monitoring sample or urine sample. Number (percent) are presented; Chi-square $\left(\chi^{2}\right)$ tests conducted to compare study cohort characteristic between the children included in the analysis and those excluded due to missing PAH indoor monitoring or urine collection within each age group.

${ }^{\mathrm{b}}$ The proportion reporting the current exposure to ETS at prenatal was statistically higher compared to those at ages 5 and 9 years $\left(\chi^{2} ; p<0.001\right)$. 

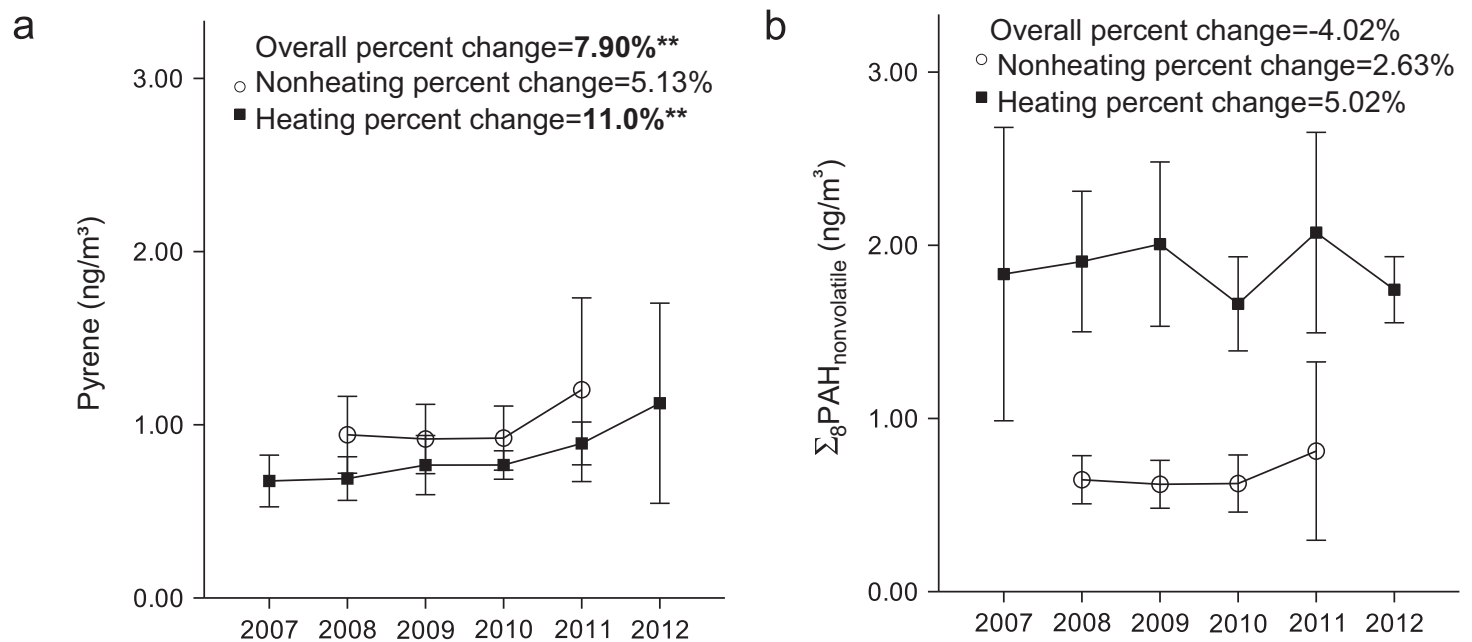

$\begin{array}{rllllll}\text { Nonheating } n= & & 12 & 10 & 11 & 8 & \\ \text { Heating } n= & 6 & 14 & 16 & 17 & 16 & 3\end{array}$

$\begin{array}{rllllll}\text { Nonheating } n= & & 12 & 10 & 11 & 8 & \\ \text { Heating } n= & 6 & 14 & 16 & 17 & 16 & 3\end{array}$

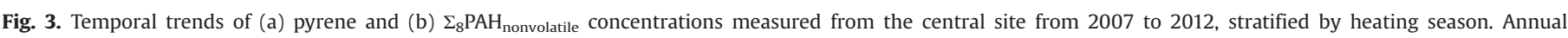

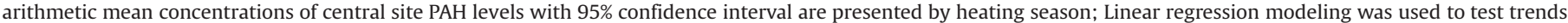

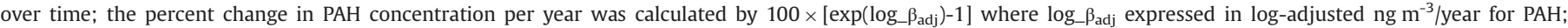
boldface type indicates statistical significance with ${ }^{* *} p$ value $<0.001$.

Table 2

Airborne data collection and prediction by location and monitoring period.

\begin{tabular}{|c|c|c|c|}
\hline \multirow{2}{*}{$\begin{array}{l}\text { Location } \\
\text { Monitoring periods }\end{array}$} & \multirow{2}{*}{$\begin{array}{l}\text { Outdoor }^{\mathrm{a}} \\
\text { 2006-2012 }\end{array}$} & \multicolumn{2}{|c|}{ Indoor $^{\mathrm{b}}$} \\
\hline & & 2005-2012 & 2001-2012 \\
\hline \multicolumn{4}{|c|}{ (2A) Summary of strata by location and monitoring period. } \\
\hline Age group(s) & $5 / 6-9 / 10 \mathrm{yr}$ & $5 / 6-9 / 10 \mathrm{yr}$ & Prenatal - 9/10 yr \\
\hline Number of observations & 195 & $527^{c}$ & $623^{\mathrm{d}}$ \\
\hline \# of repeat subjects $(\geq 2)$ & 28 & 62 & 136 \\
\hline \multicolumn{4}{|c|}{$\begin{array}{l}\text { (2B) Year of monitoring predicts } \mathrm{PAH}, \mathrm{BC} \text { and } \mathrm{PM}_{2.5} \text {. } \\
\text { Annual percent change (APC), [\%] }\end{array}$} \\
\hline$\Sigma_{8} \mathrm{PAH}_{\text {semivolatile }}{ }^{\mathrm{e}}$ & 0.70 & 7.90 & - \\
\hline PYR & $3.77^{*}$ & $4.81^{* * *}$ & $-\mathbf{2 . 7 6}$ \\
\hline$\Sigma_{8} \mathrm{PAH}_{\text {nonvolatile }}{ }^{\mathrm{f}}$ & -1.98 & -0.70 & $-4.21^{* * *}$ \\
\hline $\mathrm{BC}$ & -2.08 & $-\mathbf{2 . 0 8}$ & - \\
\hline $\mathrm{PM}_{2.5}$ & $-5.35^{* *}$ & -2.18 & - \\
\hline
\end{tabular}

-: Not available. Data were natural-log transformed and annual percent change in air pollutant concentration was calculated by $100 \times\left[\exp \left(\log \_\beta_{\text {adj }}\right)-1\right]$ where $\log \_\beta_{\text {adj }}$ expressed in log-adjusted $\mathrm{ng} \mathrm{m}^{-3} /$ year for PAHs and log-adjusted $\mu \mathrm{g} \mathrm{m}^{-3} /$ year for BC and $\mathrm{PM}_{2.5}$.

* Boldface type indicates statistical significance with $p$-value $<0.05$.

${ }^{* *}$ Boldface type indicates statistical significance with $p$-value $<0.01$.

a Generalized Estimating Equation (GEE) conducted after controlling for moved (defined as change of addresses between age 5 and 9 years), heat season and ambient ozone.

${ }^{b}$ GEE analysis conducted after controlling for race/ethnicity, maternal education, current ETS exposure, gas stove cooking, housing crowding (defined as the number of people living in the house), heat season and ambient ozone.

${ }^{\mathrm{c}}$ Reduced by $n=13$.

d Reduced by $n=15$ due to missing covariates.

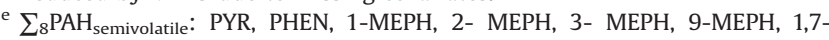
DMEPH, and 3,6-DMEPH.

${ }^{\mathrm{f}} \sum_{8} \mathrm{PAH}_{\text {nonvolatile: }} \mathrm{BaA}, \mathrm{BbFA}, \mathrm{BkFA}, \mathrm{BaP}, \mathrm{BghiP}, \mathrm{Chry}, \mathrm{DahA}$ and IP.

season (Table 3. APC $=-3.34 \%$ and $-2.66 \%$ for indoor and outdoor $\mathrm{BC}$, respectively; $p<0.05$ for both); and the increasing pyrene trends (in indoor, outdoor and central site) were more apparent in the heating season (Table 3 and Fig. 3. APC $=5.97 \%, 5.34 \%$, and $11.0 \%$ for indoor, outdoor central site pyrene, respectively; $p<0.05$ for each). Similarly, significant increasing trends were observed for most of indoor semivolatile and nonvolatile PAH in the heating season (Supplemental Table 3). Outdoor $\mathrm{PM}_{2.5}$ levels persistently decreased over time, across the seasons. When the analysis of indoor data was restricted to those measures with corresponding outdoor samples $(n=195)$, increasing trends in semivolatile PAH remained, while the declines in $\mathrm{BC}$ and $\mathrm{PM}_{2.5}$ were not apparent (data not shown). Notably, a decreasing trend was observed in pyrene over the longer period of time (2001-2012) when prenatal through age 9/10 PAH data were assessed (Fig. 4 and Table 2). This contrasted to the increases in pyrene observed between 2005 and 2012 (Table 2, APC $=-2.76 \%, p<0.01, n=623$ ). Similarly, a decreasing $\sum_{8} \mathrm{PAH}_{\text {nonvolatile }}$ trend was observed over the 20012012 period (Table 2, APC $=-4.21 \%, p<0.01$ ). Restriction to children ( $n=26 ; n=1$ with missing covariates) who were followed at all-three-age-points over a 10-11 year period yielded similar results (Supplementary Table $4, \mathrm{APC}=-5.82 \%$ and $-6.29 \%$ for

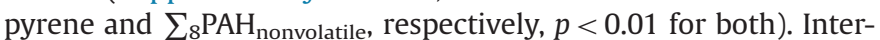
estingly, this significant decrease in pyrene and $\sum_{8} \mathrm{PAH}_{\text {nonvolatile }}$ was driven mostly by the non-heating season (Table 3, $\mathrm{APC}=-3.54 \%$ and $-7.96 \% ; p<0.001)$.

In addition to repeated air pollution measurements, associations of year of monitoring with urinary PAH metabolites were assessed after controlling for the contribution of child's age and sex and other potential covariates. Comparisons of age-specific $\mathrm{PAH}$ metabolite levels showed that levels of all hydroxy PAH except 1-naphthol, at age 9 years, were significantly higher than those at ages 3, 5 or 7 years (Supplementary Table 5). While year of monitoring positively predicted 1- hydroxypyrene and 2-naphthol levels (Fig. 5 and Supplementary Table 6, APC $=6.29 \%$ and $7.90 \%$, respectively; $p<0.01$, for both), the levels of 1-naphthol decreased from 2001 to 2012 ( $\mathrm{APC}=-9.24 \%, p<0.01)$. When the analysis was restricted to children who had data at all-four-age-points $(n=175)$, the results remained similar for 1-hydroxypyrene $(\mathrm{APC}=8.11 \% ; p<0.05)$ and 2-naphthol $(\mathrm{APC}=11.6 \% ; p<0.001)$. However, the decreasing trend in 1-naphthol became nonsignificant $(\mathrm{APC}=-7.32 \% ; p=0.078)$.

\subsection{Correlations between airborne PAH and urinary metabolites}

Levels of indoor pyrene and its metabolite 1-hydroxypyrene correlated weakly at age 5 (Supplementary Table 7; $r=0.14$; 
Table 3

Airborne data collection and variation in temporal patterns by season.*

\begin{tabular}{|c|c|c|c|c|c|c|}
\hline \multirow{3}{*}{$\begin{array}{l}\text { Season } \\
\text { Location } \\
\text { Periods }\end{array}$} & \multicolumn{3}{|c|}{ Heating season } & \multicolumn{3}{|c|}{ Nonheating season } \\
\hline & \multirow{2}{*}{$\begin{array}{l}\text { Outdoor }^{\mathrm{a}} \\
\text { 2006-2012 }\end{array}$} & \multicolumn{2}{|c|}{ Indoor $^{\mathrm{b}}$} & \multirow{2}{*}{$\begin{array}{l}\text { Outdoor }^{\mathrm{a}} \\
\text { 2006-2012 }\end{array}$} & \multicolumn{2}{|c|}{ Indoor ${ }^{\mathrm{b}}$} \\
\hline & & 2005-12 & 2001-12 & & 2006-12 & $2001-12$ \\
\hline \multicolumn{7}{|c|}{ (3A) Summary of strata by heating season, location and monitoring period. } \\
\hline Age group $(\mathrm{s})$ & $5 / 6-9 / 10$ & $5 / 6-9 / 10$ & Prenatal $-9 / 10$ & $5 / 6-9 / 10$ & $5 / 6-9 / 10$ & Prenatal - 9/10 \\
\hline Number of data & 124 & 337 & 390 & 71 & 190 & 233 \\
\hline \multicolumn{7}{|c|}{ (3B) Temporal patterns of air pollutant varied by season. } \\
\hline Season & & Heating se & & \multicolumn{3}{|c|}{ Nonheating season } \\
\hline Location & Outdoor $^{\mathrm{a}}$ & & & Outdoor $^{\mathrm{a}}$ & & \\
\hline \multirow[t]{2}{*}{ Periods } & $2006-12$ & $2005-12$ & $2001-12$ & $2006-12$ & $2006^{\mathrm{C}}-12$ & $2001-12$ \\
\hline & \multicolumn{3}{|c|}{ Annual percent change (APC), [\%] } & \multicolumn{3}{|c|}{ Annual percent change (APC), [\%] } \\
\hline$\Sigma_{8} \mathrm{PAH}_{\text {semivolatile }}{ }^{\mathrm{d}}$ & 1.31 & $9.97^{* * *}$ & - & 0.30 & 4.60 & - \\
\hline PYR & $5.34^{*}$ & $5.97^{* * *}$ & -1.98 & 1.82 & 3.05 & $-3.54^{* *}$ \\
\hline$\Sigma_{8} \mathrm{PAH}_{\text {nonvolatile }}{ }^{\mathrm{e}}$ & 1.11 & $3.87^{*}$ & -1.39 & $-7.41^{*}$ & $-8.066^{* * *}$ & $-7.96^{* * *}$ \\
\hline BC & -0.90 & -0.90 & - & $-2.66^{*}$ & $-3.34^{* * *}$ & - \\
\hline $\mathrm{PM}_{2.5}$ & $-3.25^{*}$ & -0.90 & - & $-5.82^{* *}$ & -3.05 & - \\
\hline
\end{tabular}

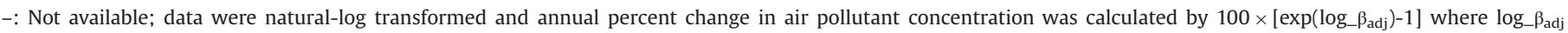
expressed in log-adjusted $\mathrm{ng} \mathrm{m}^{-3}$ /year for PAHs and log-adjusted $\mu \mathrm{g} \mathrm{m}^{-3} /$ year for $\mathrm{BC}$ and $\mathrm{PM}_{2.5}$.

* Boldface type indicates statistical significance with $p$-value $<0.05$.

** Boldface type indicates statistical significance with $p$-value $<0.01$.

a Generalized Estimating Equation (GEE) conducted after controlling for moved (which is defined as changes of addresses between age 5 and 9 years) and ambient ozone;

${ }^{\mathrm{b}}$ GEE analysis conducted after controlling race/ethnicity, maternal education, current ETS exposure, gas stove cooking, housing crowding (defined as the number of people living in the house), and ambient ozone.

${ }^{\mathrm{c}}$ Because indoor sampling was initiated October 2005 (heating season), the first nonheating season was in 2006

${ }^{d} \sum_{8} P_{A H}$ semivolatile: PYR, PHEN, 1-MEPH, 2- MEPH, 3- MEPH, 9-MEPH, 1,7-DMEPH, and 3,6-DMEPH;

e $\sum_{8} \mathrm{PAH}_{\text {nonvolatile: }} \mathrm{BaA}, \mathrm{BbFA}, \mathrm{BkFA}, \mathrm{BaP}, \mathrm{BghiP}, \mathrm{Chry}, \mathrm{DahA}$ and IP.
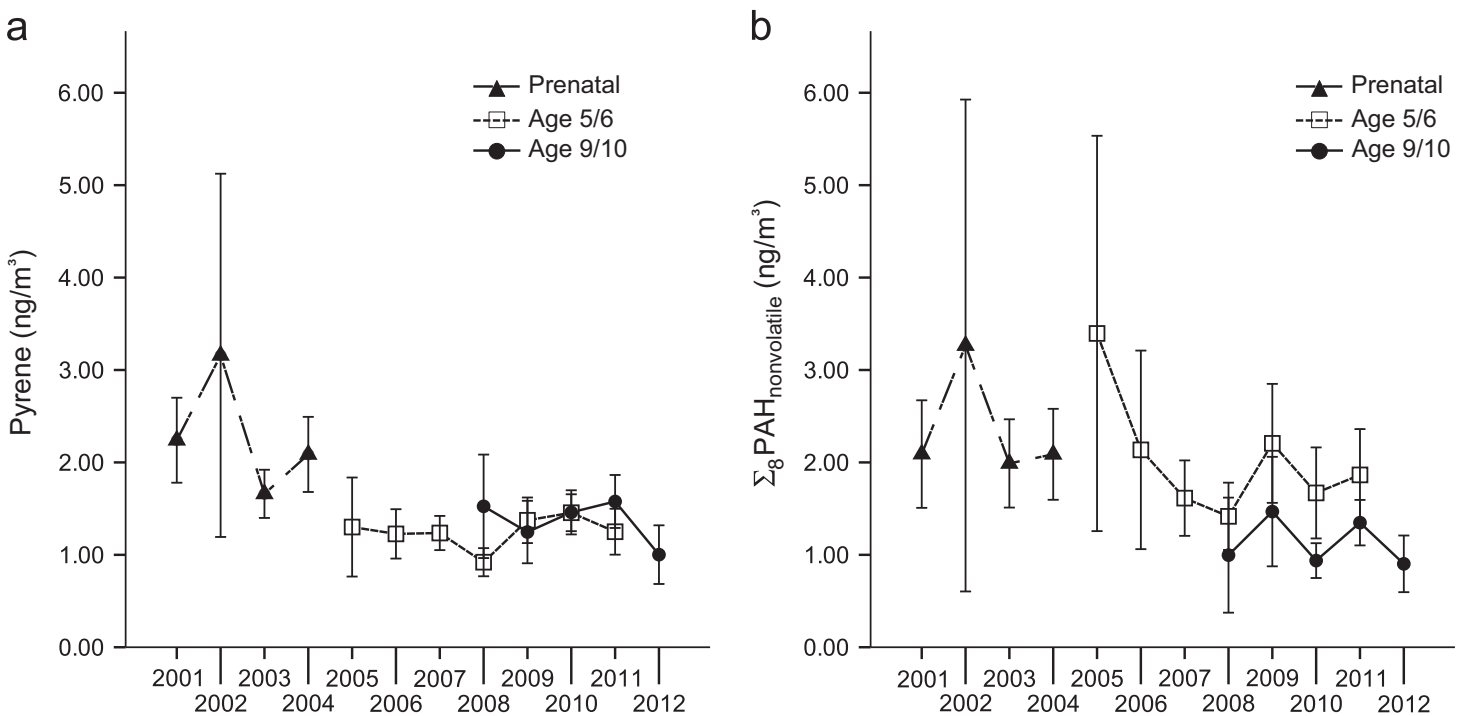

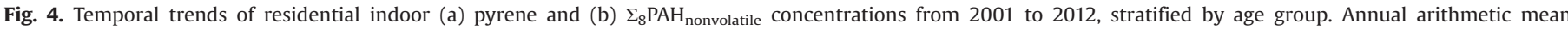
concentrations of indoor PAH levels with $95 \%$ confidence interval are presented by age group.

$p<0.05$ ), and were not correlated at age 9 years when there was a smaller number of subjects. Airborne phenanthrene and its metabolites (1-, 2-, 3-, and 4-hydroxyphenanthrenes) were only weakly correlated $(r=0.22-0.39 ; p<0.01)$ at both ages.

\section{Discussion}

Patterns of changing ambient NYC air pollution levels and their metabolites were found. They varied markedly by season, when the influence of space heating (heating season) and traffic (nonheating season) may differ in their contribution. Specifically, decreasing

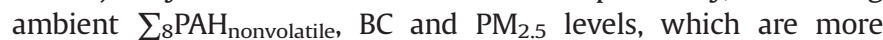
associated with traffic-related emissions and other combustion sources (Lewtas, 2007), were observed mainly in the nonheating season, while increasing ambient semivolatile PAH levels, including pyrene, from coal and heating oil and various indoor sources (Harrison et al., 1996; Jung et al., 2010a), were observed in the heating season in both indoor and outdoor samples. This pattern differed by monitoring period (e.g., 2001-2012 vs. 2005-2012), particularly for pyrene. We also found significant increases in 
a

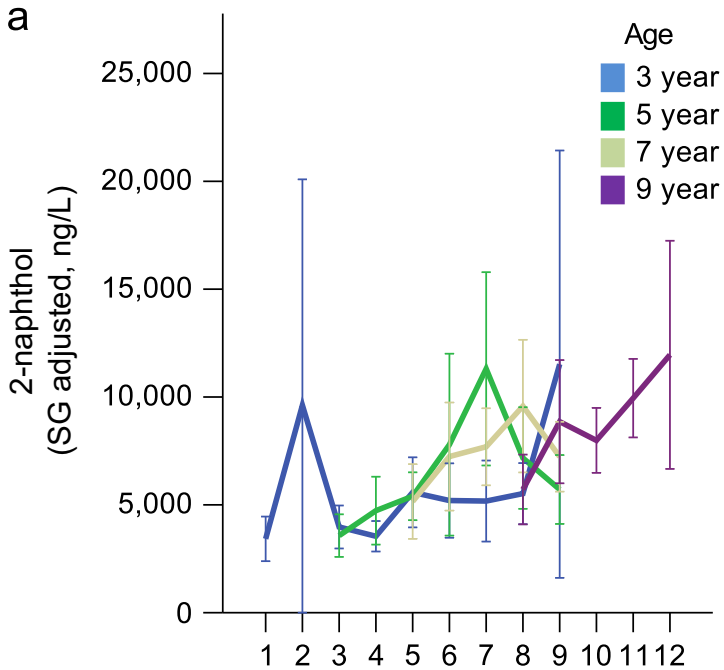

b

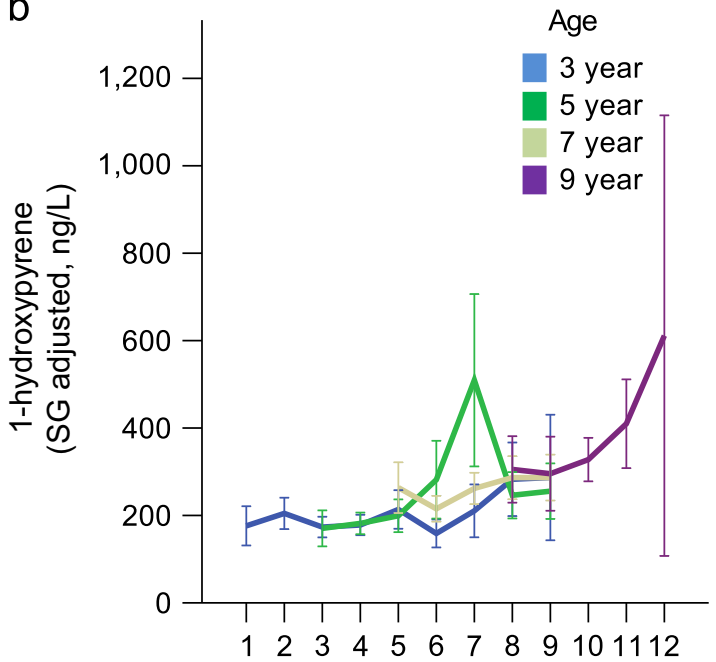

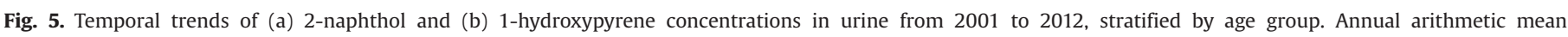

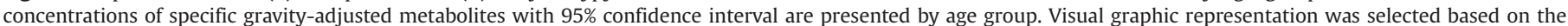
significance of positive associations between year of monitoring and PAH metabolites shown in Supplementary Table 6.

1-hydroxypyrene and 2-naphthol levels, urinary metabolites of pyrene and naphthalene, respectively, measured in urine collected from young children between 2001 and 2012.

In contrast to our previous analysis of annual trends in personal PAH levels measured from different individuals (Narvaez et al., 2008), this study has the advantage of avoiding changes that could be due to variations in personal behaviors/activities, and is more likely to reflect variations in ambient PAH levels associated with policy interventions. The strengths of this study also include our ability to (1) follow the same children over up to a 10-11 year period, (2) analyze additional data available in various sampling matrices such as air monitoring (i.e., residential indoor, outdoor, and the central monitoring conducted with the same methodology) and bio-monitoring (i.e. urinary metabolites), (3) control for concurrent ambient ozone concentrations that can alter outdoor $\mathrm{PAH}$ and penetrate into indoor environment (Stephens et al., 2011) where it can further react with indoor PAH, and (4) control for indoor sources (e.g., current ETS exposure and gas stove cooking etc) that strongly impact the levels of air pollution, to understand better time trends of PAH influenced by traffic and other outdoor sources.

The distinct declines of residential indoor $\sum_{8} \mathrm{PAH}_{\text {nonvolatile }}$ and BC detected between 2005 and 2012, much of which can penetrate readily from outdoor sources (Jung et al., 2010a), were mostly driven by measures from the nonheating season when fuel oil is not used for space heating. This finding implies that the significant decrease in $\sum_{8} \mathrm{PAH}_{\text {nonvolatile }}$ and $\mathrm{BC}$ was a result of decreases in the traffic emissions following legislation to reduce traffic-related air pollution. Nevertheless, it is important to note that the beginning (2005) and the end (2012) of air monitoring year exhibited the highest and the lowest annual mean concentrations, respectively, likely driving the decreasing trends of $\sum_{8} \mathrm{PAH}_{\text {nonvolatile }}$ and BC. Given the large error bars seen at both ends due to a small sample size, these results should be interpreted cautiously. However, the absence of a decrease in outdoor $\sum_{8} \mathrm{PAH}_{\text {nonvolatile }}$ and $\mathrm{BC}$, and increasing trend of indoor $\sum_{8} \mathrm{PAH}_{\text {nonvolatile during the heating }}$ season may be explained by increased emissions from heating oil combustion. In comparison, a significant decrease was not observed in ambient central site data, possibly due to a much smaller sample size. The declines in $\mathrm{PM}_{2.5}$ were apparent both in the ambient central site and residential outdoor air. This decline may be a result of the conversion to ultralow sulfur diesel fuel and associated reductions in upwind sulfur emissions, the largest contributor to ambient $\mathrm{PM}_{2.5}$ in the NYC area. This decreasing trend of $\mathrm{PM}_{2.5}$ was supported further by our previous observation of significant decreases in ambient $\mathrm{PM}_{2.5}$ levels measured from two monitoring sites (I.S.52 and Morrisania) in the Bronx, NY between 1999 and 2010 (Kuang et al., 2012).

We observed an increasing trend for pyrene mostly during the heating season in the central site as well as in residential outdoor and indoor for comparable time periods (2005-2012). Considering pyrene as a tracer of coal (Harrison et al., 1996) and oil combustion (Kraus and Coburn, 1974), a rise in pyrene concentration during the heating season could be due to an increase in emissions from residential fuel oil and coal combustion for space heating that is known to be one of the major sources for PAH in NYC (Yan et al., 2005). In recent years, major heating oil companies in NYC have sold No. 4 and No. 6 fuel oil that was mixed with recycled or waste oil such as used car engine oil and sludge residue from commercial boilers (The New York Times, 2013). Burning of more contaminated dirty heating oil and thus producing more byproducts could explain the upward trend in pyrene during the heating season over the 2005-2012 period. Also, other covariates such as the use of gas stove for cooking and housing crowding used as a proxy for indoor activity levels, were predictive of the increases in indoor pyrene levels, indicating the contribution of indoor sources to pyrene. In exploratory analyses, we observed that the median I/O ratios of pyrene obtained between 2006 and 2012 increased gradually with time (data not shown), further supporting the enhanced contribution of indoor sources to pyrene. Unlike other nonvolatile $\mathrm{PAH}, \mathrm{BC}$ and $\mathrm{PM}_{2.5}$, we did not observe decreases in pyrene and other semivolatile PAH levels, even during the nonheating season in any air sampling matrices over the 2005-2012 period. Given the substantially higher levels of semivolatile PAH observed during the nonheating versus the heating season (Jung et al., 2010a), it is possible that temperaturedriven outgassing of these compounds (e.g., enhanced petrogenic emissions such as evaporation from petroleum products and contaminated soil) overwhelmed the traffic-related declines during the nonheating season. However, pyrene exhibited a downward trend over the longer period of time (2001-2012), mostly driven by measures from the nonheating season. ETS was a significant predictor of pyrene $\left(\beta_{\mathrm{adj}}=0.210, p=0.008\right)$ in the models, and a decrease in current ETS (Table 1, 36.1\% [prenatal] to $12.1 \%$ [age 9]) was measured, suggesting that the decline in pyrene can be explained 
partly by reduced exposure to current ETS exposure. Altogether, our results likely reflect that (1) a decreasing pattern of indoor pyrene levels was driven by the rapid declines in the 'earlier' (2001-2005) periods as shown in Figs. 4 and 2 reductions in pyrene in the earlier periods occurred as a result of policy initiatives such as use of cleaner fuels and better engines or decreases in current ETS exposure.

In contrast to the overall decreases in airborne pyrene between 2001 and 2012, levels of urinary 1-hydroxypyrene, the principal product of pyrene metabolism, increased over time, consistent with the increasing trends observed in the smaller data sets of indoor and outdoor levels between 2005 and 2012 (Table 2B). 1-hydroxypyrene and phenanthrene metabolites, considered biomarkers of exposure from all sources (e.g., inhalation, ingestion, and dermal absorption), were well-correlated with the amount of ingested parent $\mathrm{PAH}$, but not the amount of the parent ambient PAH inhaled (Li et al., 2010, 2012). In this study, 1-hydroxypyrene urinary measures correlated only minimally with levels of pyrene in indoor air as well $(r=0.13-0.14$ at age 9 and 5 years, respectively), suggesting that diet as opposed to inhalation may be the dominant route of exposure for pyrene. The major exposure route for two naphthalene metabolites, 1-naphthol and 2-naphthol, is inhalation in non-occupational settings (Li et al., 2010, 2012). Moderate to strong correlations $(r=0.42-0.89)$ between airborne naphthalene and two naphthalene metabolites (Li et al., 2010, 2012) support this explanation. Therefore, the urinary naphthols may better indicate airborne PAH levels than the other semivolatile PAH metabolites tested. In this study, a divergent time trend was observed for the urinary naphthols: a decrease in 1-naphthol and an increase in 2-naphthol. While 2-naphthol has been proposed as a biomarker for exposure to ambient naphthalene (Li et al., 2012), 1-naphthol is believed to be indicate exposure form both naphthalene and the insecticide carbaryl (1-naphyl$\mathrm{N}$-methylcarbamate) (Maroni et al., 2000). Therefore, a decrease in 1-naphthol may be a result of a decrease in carbaryl use in the residential environment. In contrast, the increase in 2-naphthol may be attributed to increases in ambient emissions and those from common indoor sources such as cooking, heating, use of naphthalene-containing repellent (mothballs), and petrochemicals used indoors (ATSDR, 2005).

We acknowledge several limitations to the study. First, the data are not derived from repeat sampling of all the same children. However, the results from the analysis restricted to those children who were followed at all time-points (both indoor air and urine samples) remained very similar despite the very small sample size. Second, ambient outdoor monitoring, compared to indoor data that are more variable due to potential indoor sources and subject characteristics, can provide more direct trends of ambient air pollution; however, the smaller sample size for the central site and outdoor sampling (relative to indoor sampling) limited our statistical power for many analyses. Notwithstanding, the temporal declines in BC and nonvolatile PAH detected in indoor air demonstrates reductions in traffic-related sources because indoor BC and nonvolatile PAH can be attributed mostly to the infiltration of outdoor air (Jung et al., 2010a). Third, it is not clear when distribution of fuel mixed with waste oil began in NYC. Further, there is no evidence that PAH sources increased during the sampling periods (2005-2012). Fourth, we observed a batch effect in the PAH analysis. After adjustment for the batch effect, the results of annual trends of indoor pyrene and $\sum_{8} \mathrm{PAH}_{\text {nonvolatile }}$ remained essentially the same: a significant increasing trend of pyrene $(A P C=5.34 \%$, $p<0.01)$ and nonsignificant decreasing trend of $\sum_{8} \mathrm{PAH}_{\text {nonvolatile }}$ $(\mathrm{APC}=-2.86 \%, p>0.05)$ were observed between 2005 and 2012. Fifth, we did not control for dietary intake of PAH exposure. Nevertheless, 2-naphthol, the metabolite of inhaled naphthalene, increased over time, suggesting a greater contribution of indoor and outdoor sources to naphthalene. Lastly, the half-lives of PAH metabolites are relatively short, ranging from 2.5-6.1 h among the10 PAH metabolites, with the shorter $t_{1 / 2}$ of $2.5 \mathrm{~h}$ in 2-naphthol (Li et al., 2012); hence, they may not be representative of long-term PAH exposure.

\section{Conclusion}

To our knowledge, this is the first study to examine temporal trends of PAH levels in urine and indoor/outdoor air using repeat measures from homes of young urban children. We found decreases in levels of the traffic-related air pollutants, $\sum_{8} \mathrm{PAH}_{\text {nonvolatile, }} \mathrm{BC}$ and $\mathrm{PM}_{2.5}$ mostly driven by observations made in the nonheating season, suggesting declines in traffic emission following multiple legislative regulations in NYC. Despite this encouraging finding on traffic-related air pollution during the nonheating season, pyrene levels increased in recent years. Elevation over time in both pyrene and 2-naphthol indicates the contribution of heating oil combustion and other indoor sources to airborne pyrene and urinary 2-naphthol levels.

\section{Conflicts of interest statement}

None of the authors has a financial relationship with a commercial entity that has an interest in the subject of this manuscript.

\section{Disclaimer}

The content is solely the responsibility of the authors and does not necessarily represent the official position of the Centers for Disease Control and Prevention.

\section{Funding sources}

This work was supported by NIH (R01ES013163, P50ES015905, P01ES09600, R01ES08977, P30ES09089), EPA (R827027, RD832096, RD832141, RD834509), the Educational Foundation of America, the John \& Wendy Neu Family Foundation, the New York Community Trust, and the Trustees of the Blanchette Hooker Rockefeller Fund.

\section{Appendix A. Supporting information}

Supplementary data associated with this article can be found in the online version at http://dx.doi.org/10.1016/j.envres.2014.02.017.

\section{References}

ATSDR, 2005. Toxicological Profile for Naphthalene, 1-Methylnaphthalene, and 2-Methylnaphthalene. Agency for Toxic Substances and Disease Registry, Atlanta. 〈http://www.atsdr.cdc.gov/toxprofiles/tp.asp?id=240\&tid=43〉 (accessed 04.06.13)

Cornell, A.G., et al., 2012. Domestic airborne black carbon and exhaled nitric oxide in children in NYC. J. Expo. Sci. Environ. Epidemiol. 22, 258-266.

Cyrys, J., et al., 2003. Comparison between different traffic-related particle indicators: elemental carbon (EC), PM2.5 mass, and absorbance. J. Expo. Anal. Environ. Epidemiol. 13, 134-143.

Harrison, R.M., et al., 1996. Source apportionment of atmospheric polycyclic aromatic hydrocarbons collected from an urban location in Birmingham, UK. Environ. Sci. Technol. 30, 825-832.

Hauser, R. et al., 2004. Temporal variability of urinary phthalate metabolite levels in men of reproductive age. Environ. Health Perspect. 112, 1734

Jung, K.H., et al., 2010a. Effects of heating season on residential indoor and outdoor polycyclic aromatic hydrocarbons, black carbon, and particulate matter in an urban birth cohort. Atmos. Environ, 44, 4545-4552.

Jung, K.H., et al., 2010b. Assessment of benzo (a) pyrene-equivalent carcinogenicity and mutagenicity of residential indoor versus outdoor polycyclic aromatic hydrocarbons exposing young children in New York City. Int. J. Environ. Res. Publ. Health 7, 1889-1900. 
Jung, K.H., et al., 2012a. Childhood exposure to fine particulate matter and black carbon and the development of new wheeze between ages 5 and 7 in an urban prospective cohort. Environ. Int. 45, 44-50.

Jung, K.H., et al., 2012b. Repeated exposure to polycyclic aromatic hydrocarbons and asthma: effect of seroatopy. Ann. Allergy Asthma Immunol. 109, 249-254.

Kinney, P.L., et al., 2002. Exposures to multiple air toxics in New York City. Environ. Health Perspect. 110 (Suppl 4), 539-546.

Kraus, B., Coburn, J., 1974. Emissions from domestic heating oil combustion. Am. Chem. Soc., Div. Fuel Chem. 19, 49-54.

Kuang, F.L., et al., 2012. Annual New York City trends of ambient fine particulate matter, elemental carbon and metals implicated in airway disease. J. Allergy Clin. Immunol. 129, AB204.

Lall, R., et al., 2011. Distributed lag analyses of daily hospital admissions and sourceapportioned fine particle air pollution. Environ. Health Perspect. 119, 455.

Lewtas, J., 2007. Air pollution combustion emissions: characterization of causative agents and mechanisms associated with cancer, reproductive, and cardiovascular effects. Mutat. Res.-Rev. Mutat. Res. 636, 95-133.

Li, Z., et al., 2006. Measurement of urinary monohydroxy polycyclic aromatic hydrocarbons using automated liquid-liquid extraction and gas chromatography/isotope dilution high-resolution mass spectrometry. Anal. Chem. 78, 5744-5751.

Li, Z., et al., 2010. Assessment of non-occupational exposure to polycyclic aromatic hydrocarbons through personal air sampling and urinary biomonitoring. J. Environ. Monit. 12, 1110-1118.

Li, Z., et al., 2012. Excretion profiles and half-lives of ten urinary polycyclic aromatic hydrocarbon metabolites after dietary exposure. Chem. Res. Toxicol. 25, 1452-1461.

MTA. New York City Transit and the Environment. The Clean Fuel Bus Program. Available from:〈http://web.mta.info/nyct/facts/ffenvironment.htm\#clean_bus (accessed 22.07.13).

Ma, W.-L., et al., 2010. Seasonal variations of sources of polycyclic aromatic hydrocarbons (PAHs) to a northeastern urban city, China. Chemosphere 79, 441.

Maroni, M., et al., 2000. Biological monitoring of pesticide exposure: a review. Introduction. Toxicology 143, 1.

Miller, R., et al., 2010. Polycyclic aromatic hydrocarbon metabolite levels and pediatric allergy and asthma in an inner city cohort. Pediatr. Allergy Immunol. 21, 260-267.
Miller, R.L., et al., 2004. Polycyclic aromatic hydrocarbons, environmental tobacco smoke, and respiratory symptoms in an inner-city birth cohort. Chest 126, 1071-1078.

Narvaez, R.F., et al., 2008. Spatial and temporal trends of polycyclic aromatic hydrocarbons and other traffic-related airborne pollutants in New York City. Environ. Sci. Technol. 42, 7330-7335.

Perzanowski, M.S., et al., 2013. Early-life cockroach allergen and polycyclic aromatic hydrocarbon exposures predict cockroach sensitization among inner-city children. J. Allergy Clin. Immunol. 131, 886-893.

Rosa, M.J., et al., 2011. Prenatal exposure to polycyclic aromatic hydrocarbons, environmental tobacco smoke and asthma. Respir. Med. 105, 869-876.

Rundle, A., et al., 2012. Association of childhood obesity with maternal exposure to ambient air polycyclic aromatic hydrocarbons during pregnancy. Am. J. Epidemiol. 175, 1163-1172.

Spira-Cohen, A., et al., 2011. Personal exposures to traffic-related air pollution and acute respiratory health among Bronx school children with asthma. Environ. Health Perspect. 119, 559-565.

Spurr, G., et al., 1992. Basal metabolic rate of Colombian children 2-16 y of age: ethnicity and nutritional status. Am. J. Clin. Nutr. 56, 623-629.

Stephens, B., et al., 2011. Measuring the penetration of ambient ozone into residential buildings. Environ. Sci. Technol. 46, 929-936.

The New York Times. Heating Oil Companies Face Inquiry on Purity of Fuel. Available from: 〈http://www.nytimes.com/ (accessed 25.03.13).

Whyatt, R.M., et al., 2007. Within-and between-home variability in indoor-air insecticide levels during pregnancy among an inner-city cohort from New York City. Environ. Health Perspect. 115, 383.

Yan, B., et al., 2005. Molecular tracers of saturated and polycyclic aromatic hydrocarbon inputs into Central Park Lake, New York City. Environ. Sci. Technol. 39, 7012-7019.

Yan, B., et al., 2011. Validating a nondestructive optical method for apportioning colored particulate matter into black carbon and additional components. Atmos. Environ. 45, 7478-7486.

Zhang, Y., Tao, S., 2009. Global atmospheric emission inventory of polycyclic aromatic hydrocarbons (PAHs) for 2004. Atmos. Environ. 43, 812-819. 